\title{
Cellulose Acetate Propionate Coated Titanium: Characterization and Biotechnological Application
}

\author{
Guilherme da Silva Gomes ${ }^{\mathrm{a}}$, Arlete Tavares de Almeida ${ }^{\mathrm{a}, \mathrm{b}}$, Priscila Monteiro Kosaka ${ }^{\mathrm{a}}$, Sizue Ota Rogero ${ }^{\mathrm{c}}$, \\ Áurea Silveira Cruz ${ }^{\mathrm{d}}$, Tamiko Ichikawa Ikeda ${ }^{\mathrm{d}}$, Denise Freitas Siqueira Petri ${ }^{\mathrm{a} *}$ \\ ${ }^{a}$ Instituto de Química, Universidade de São Paulo - USP, \\ Av Prof Lineu Prestes, 748, 05508-900 São Paulo - SP, Brazil \\ ${ }^{\mathrm{b}}$ Orbys Desenvolvimento de Tecnologia de Materiais Ltda, São Paulo - SP, Brazil \\ ${ }^{c}$ Instituto de Pesquisas Energéticas e Nucleares - IPEN/CNEN, São Paulo - SP, Brazil \\ dinstituto Adolfo Lutz, São Paulo - SP, Brazil
}

Received: August 10, 2007; Revised: November 20, 2007

\begin{abstract}
Surfaces of pure titanium and Ti coated with cellulose acetate propionate (CAP) have been characterized by means of scanning electron microscopy X ray coupled with elemental microanalysis (SEM-EDS), ellipsometry, atomic force microscopy (AFM) and contact angle measurements. Coating Ti surfaces with CAP ultrathin films reduced original surface roughness. Surface energy and wettability of CAP covered Ti surfaces pure Ti surfaces were similar. The adsorption of lysozyme (LYZ), an antibacterial protein, onto Ti and CAP-coated Ti surfaces has been studied by means of ellipsometry and atomic force microscopy (AFM). The adsorption of LYZ was mainly driven by hydrophobic interaction between protein hydrophobic residues and CAP propyl groups. Pure Ti and CAP coated Ti surfaces presented no cytotoxicity effect and proved to be adequate substrates for cell adhesion. The biocompatibility of CAP coated Ti surfaces was attributed to the surface enrichment in glucopyranosyl residues and short alkyl side groups.
\end{abstract}

Keywords: titanium, cellulose acetate propionate, lysozyme, cell adhesion

\section{Introduction}

Titanium and titanium alloys have been widely used in implants due to their characteristics, such as early osseointegration, mechanical resistance, non-toxicity,among many others ${ }^{1}$. Surface chemical composition and roughness control implant performance, because interactions between implant and proteins, biological fluids, cell and tissues depend on the surface wettability ${ }^{2,3}$ and topological aspects ${ }^{1,3,4}$. Many efforts have been made for improving Ti based implants performance; most of them involve surface modification for controlling cell and tissue responses. Coating Ti implants with layers of calcium phosphates mainly composed of hydroxyapatite has been frequently done. Positive and negative aspects of such strategy have been well discussed in a recent review ${ }^{1}$. Platelet adhesion has been observed for hyaluronan covalently coupled to stainless steel surfaces via a silane coupling layer ${ }^{5}$.

In general the success of biomaterials depends on the interaction between surface material and protein layer and their adhesives properties for cells. However, this link remains far from being understood $^{6}$. Cellulose acetate propionate (CAP) belongs to cellulose ester family, which presents large field of biotechnological applications due to their biocompatibility ${ }^{7}$. For instance, it has been used as enteric coating of drugs, which should survive the acidic environment of the stomach, but should be released and absorbed in the intestines ${ }^{7}$. Moreover, CAP coatings have proven to work efficiently for selective protein adsorption ${ }^{8}$. The main goal of this work is to modify Ti surfaces with CAP and to study (i) the adsorption of lysozyme (LYZ), an antibacterial protein', and cell adhesion onto CAP-coated Ti surfaces. $\mathrm{X}$ ray microanalysis (SEM-EDS), atomic force microscopy (AFM) and contact angle measurements were used to characterize Ti and CAP-coated Ti surfaces. LYZ adsorption onto Ti and CAP-coated Ti surfaces has been studied by means of ellipsometry and AFM. Moreover, cytotoxicity test and cell adhesion assay were also performed.

\section{Experimental}

\subsection{Materials}

Disc-shaped samples of Ti having a nominal area of $0.5 \mathrm{~cm}^{2}$ were kindly supplied by Sistema de Implante Nacional (SIN, São Paulo, Brazil). Supplier has mechanically polished both faces of Ti discs. Prior to coating experiments $\mathrm{Ti}$ discs were rinsed with analytical grade acetone and characterized.

Cellulose acetate propionate (CAP, CAP-482-0.5) free of plasticizer was kindly supplied by Eastman Chemical Co., Brazil. CAP presented weight-average molecular weight $\left(\overline{\mathrm{M}}_{\mathrm{w}}\right)$ of $\sim 25,000 \mathrm{~g} \cdot \mathrm{mol}^{-1}$, degree of esterification for acetate and propionate as 0.2 and 2.3 , respectively, and degree of hydroxyl as 0.5 . The degree of esterification is the ratio of ester groups to glucose residues. Analytical grade ethyl acetate was used to prepare the solutions at the polymer concentration of $10 \mathrm{mg} \cdot \mathrm{mL}^{-1}$. CAP chemical structure is schematically represented in the Supplementary Material.

Lysozyme (LYZ, Sigma L-7001, Lot 121K7079) from chicken egg white, a basic protein (positively charged) with isoelectric point (pI) 10.7 11.0 and $\mathrm{M} \sim 14,400 \mathrm{~g} \cdot \mathrm{mol}^{-1}{ }^{10}$ was used without purification. 


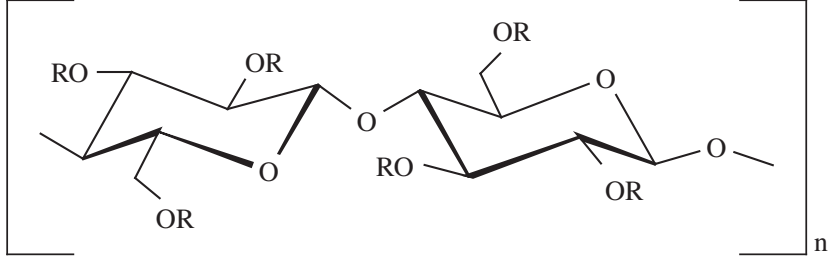

Supplementary material. Schematic representation of the chemical structure of $\mathrm{CAP}, \mathrm{R}=\mathrm{COCH}_{2} \mathrm{CH}_{3}$.

\subsection{Methods}

\subsubsection{Spin-coating of CAP onto Ti discs}

Solutions of CAP were prepared in ethyl acetate at concentration of $10 \mathrm{mg} / \mathrm{mL}$ and spin-coated onto Ti surfaces, using a Headway PWM32-PS-R790 spinner (Garland, USA), operating at $3000 \mathrm{rpm}$ during 30 seconds, $(24 \pm 1)^{\circ} \mathrm{C}$ and $(50 \pm 5) \%$ of relative humidity. After that, the samples were annealed for 15 hours at $170{ }^{\circ} \mathrm{C}$ in a vacuum oven in order to release stress during film formation ${ }^{8}$.

Ellipsometry - Ellipsometric measurements were performed in air using a vertical computer-controlled DRE-EL02 ellipsometer (Ratzeburg, Germany). The angle of incidence was set at $70.0^{\circ}$ and the wavelength, $\lambda$, of the He-Ne laser was $632.8 \mathrm{~nm}$. For the data interpretation, a multilayer model composed by the substrate, the unknown layer and the surrounding medium should be used. Then the thickness $\left(d_{x}\right)$ and refractive index $\left(\mathrm{n}_{\mathrm{x}}\right)$ of the unknown layer can be calculated from the ellipsometric angles, $\Delta$ and $\Psi$, using the fundamental ellipsometric equation and iterative calculations with Jones matrices ${ }^{11}$ :

$$
\mathrm{e}^{\mathrm{i} \Delta} \tan \Psi=\mathrm{R}_{\mathrm{p}} / \mathrm{R}_{\mathrm{s}}=\mathrm{f}\left(\mathrm{n}_{\mathrm{k}}, \mathrm{d}_{\mathrm{k}}, \lambda, \phi\right)
$$

where $R_{p}$ and $R_{s}$ are the overall reflection coefficients for the parallel and perpendicular waves. They are a function of the angle of incidence $\phi$, the wavelength $\lambda$ of the radiation and of the refractive index and the thickness of each layer of the model, $n_{k}, d_{k}$.

From the ellipsometric angles $\Delta$ and $\Psi$ and a multilayer model composed by Ti, polysaccharide layer and air it is possible to determine only the thickness of the polysaccharide layer, dpoly. The refractive indices used for Ti and air were $\tilde{n}=3.23-\mathrm{i} 3.62^{12}$ and $\tilde{\mathrm{n}}=1.00$, respectively. The mean thickness of annealed CAP layers was determined in air, considering the nominal refractive index of $1.475^{8}$.

The adsorption experiments were carried out by dipping CAP coated Ti surfaces into LYZ solution during 3 hours, since after this time no changes in the thickness of adsorbed layer could no longer be observed. LYZ solutions were prepared in water, $\mathrm{NaCl} 0.1 \mathrm{~mol} . \mathrm{L}^{-1}$ or $\mathrm{NaCl} 0.2$ mol. $\mathrm{L}^{-1}$ in the concentration range 0.050 to $1.0 \mathrm{~g} . \mathrm{L}^{-1}$, under $\mathrm{pH}$ 6. After 3 hours of adsorption the samples were removed from the solution, rinsed in the pure solvent, dried under a stream of $\mathrm{N}_{2}$ and characterized. The mean thickness of adsorbed protein layers was determined in air, considering the nominal refractive index of 1.520. The adsorbed amount $\Gamma$ was determined by multiplying the mean thickness $d$ by the density of proteins $\left(\rho=1.37 \text { g.cm }{ }^{-3}\right)^{8,13,14}$.

All ellipsometric data were collected as triplicates from at least two independent experiments.

Scanning Electron Microscopy (SEM) with Energy Dispersive $\mathrm{X}$ ray Spectroscopy (EDS) has been performed in a JEOL 7401-F equipment. The samples were analyzed without any special treatment or coating. Analyses were carried out with at least two samples of the same material, scanning different areas of the each surface.

Atomic Force Microscopy (AFM) measurements were performed in a PICO SPM-LE (Molecular Imaging) microscope in the intermittent contact in air at room temperature, using silicon cantilevers with resonance frequency close to $300 \mathrm{kHz}$. Images were obtained with a resolution of $512 \times 512$ pixels. Image processing and the determination of root mean square roughness (rms) were performed using the Pico Scan software. At least two films of the same composition were analyzed at different areas of the surface.

Contact angle measurements were performed at $(24 \pm 1){ }^{\circ} \mathrm{C}$ in a home-built apparatus. Sessile water drops of water of 8 and $4 \mu \mathrm{L}$ were used for the advancing $\left(\theta_{A}\right)$ and the receding $\left(\theta_{R}\right)$ contact angle, respectively. The hysteresis in the contact angle $\left(\Delta \theta=\theta_{A}-\theta_{R}\right)$ stems from surface roughness or surface chemical heterogeneity ${ }^{15}$. At least three samples of the same composition were analyzed before and after the annealing process.

\subsubsection{Cytotoxicity}

Cytotoxicity assay was carried out by agar diffusion technique ${ }^{16}$ according to International Standard ISO $10993^{17}$. Cell line (NCTC clone L-929) from American Type Culture Collection bank was used during the tests. $5 \mathrm{~mL}$ of cell suspension $\left(3 \times 10^{5}\right.$ cells. $\left.\mathrm{mL}^{-1}\right)$ in culture medium MEM (minimum Eagle's medium, Sigma Co., USA) with $10 \%$ fetal calf serum were seeded in Petri dishes $(15 \times 60 \mathrm{~mm})$ and incubated during 48 hours in a humidified incubator with $5 \% \mathrm{CO}_{2}$ atmosphere at $37^{\circ} \mathrm{C}$ to obtain cellular monolayer. After this period the culture medium was replaced by $5 \mathrm{~mL}$ of overlay medium composed by two times concentrated MEM and $1.8 \%$ agar solution with $0.01 \%$ neutral red $(1: 1)$ at $44{ }^{\circ} \mathrm{C}$. Before complete agar solidification the samples were put on the top of the agar surface. Rubber latex and no toxic filter paper disc with the same dimension of samples were used as positive and negative control, respectively. After $24 \mathrm{~h}$ of incubation, Petri dishes were analyzed macro and microscopically and the cytotoxic effect was evaluated measuring the diameter of clear halo around tested material.

\subsubsection{Cell adhesion}

$100 \mu \mathrm{L}$ of cell (NCTC clone L-929) suspension $\left(3 \times 10^{5}\right.$ cells.mL $\left.{ }^{-1}\right)$ in culture medium MEM with $10 \%$ fetal calf serum were seeded in Petri dishes $(15 \times 60 \mathrm{~mm})$ containing six bare Ti discs or six CAP-coated Ti discs or LYZ/CAP-coated Ti discs. They have been incubated during 48 hours in a humidified incubator with $5 \% \mathrm{CO}_{2}$ atmosphere at $37{ }^{\circ} \mathrm{C}$ to obtain cellular monolayer. After this period the culture medium each sample has been rinsed with PBS buffer and introduced into glass tubes containing $1.0 \mathrm{~mL}$ ATV (trypsin $0.2 \%$ and versene $^{\mathrm{TM}} 0.02 \%$ ) to promote for cell detachment. After cell detaching, $0.5 \mathrm{~mL}$ of cell suspension was added to $1.5 \mathrm{~mL}$ of gentian violet ( $0.1 \%$ solution). Cell concentrations were then determined by means of a Neubauer-counting chamber.

\section{Results and Discussion}

\subsection{Substrates characterization}

Implant surface profiles might play an important role on the adhesion of cells and proteins. Ti disc surfaces have been analyzed by SEM-EDS. Ti surfaces presented many large scratches (Figure 1), which were probably produced during mechanical polishing process. Elemental analysis (Figure 2) indicated that the surfaces are composed of $99.6 \%$ of Ti and $0.4 \%$ of Al. This low amount of Al might stem from sample support, which contains $\mathrm{Al}$ as well. AFM topographic images (Figure 3a) were obtained for Ti areas much smaller than those observed by SEM (Figure 1). For instance, Figure 3a corresponds to a scan area of $20 \times 20 \mu \mathrm{m}$. The corresponding mean roughness value (rms) amounted to $\sim 32 \mathrm{~nm}$. In comparison to Si wafers, which are very flat surfaces with typical rms values of $0.2 \mathrm{~nm}$ for similar scan area, Ti discs are very rough, also in the nanometer scale. Figure $3 \mathrm{~b}$ shows a typical 
topographic image obtained for LYZ adsorbed onto Ti substrate. High structures, as aggregates, are observed. They could be assigned either to the adsorbed entities or to Ti surface topography. Since proteins are very small molecules with typical radius of gyration ranging from 2 to $5 \mathrm{~nm}$, keeping the substrate surface profiles in the nanometer range is very important to quantify accurately the amount of adsorbed proteins. Ellipsometry and AFM are techniques that allow the determination of very small layer thickness and direct visualization of the adsorbed protein molecules, if the surfaces are not too rough.

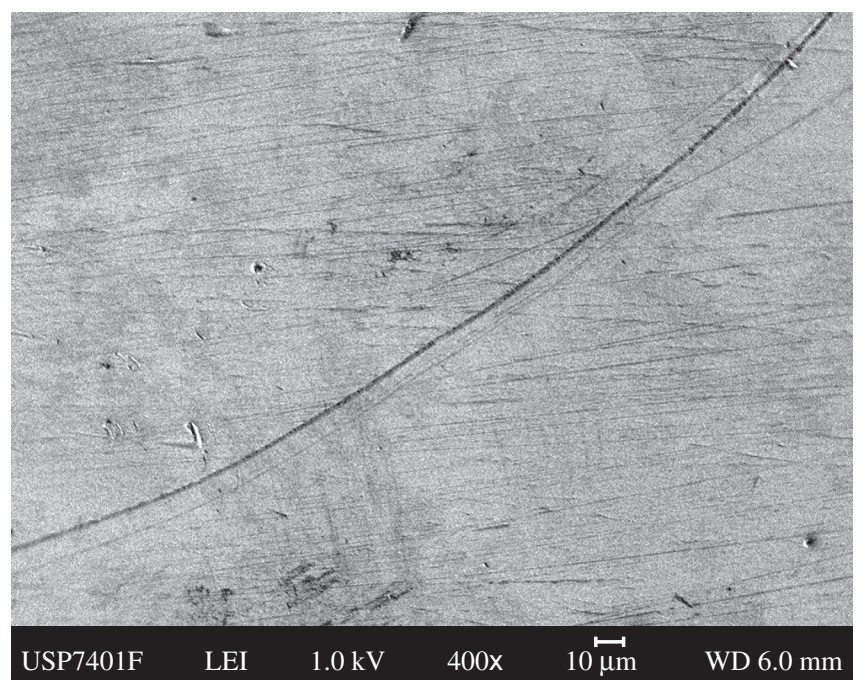

Figure 1. Typical SEM obtained for pure Ti surface. Scanned area corresponds to $230 \times 319 \mu \mathrm{m}$.

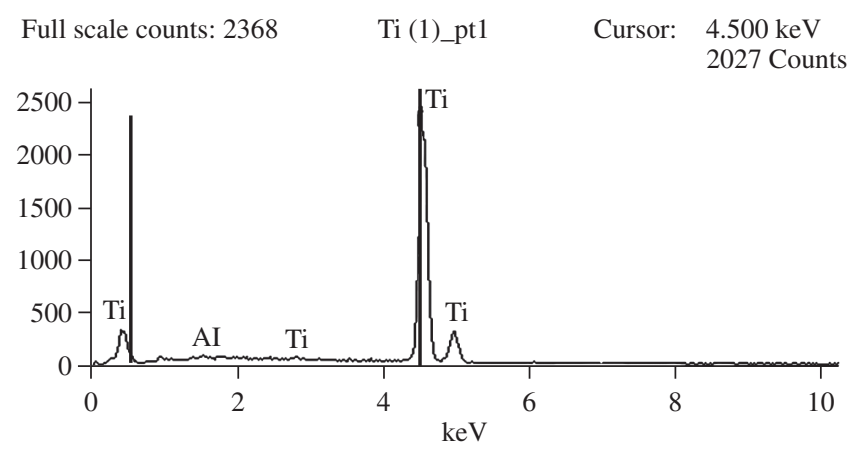

$\mathrm{klm}-8-0$

\begin{tabular}{|c|c|c|}
\hline \multicolumn{3}{|c|}{ Net Counts } \\
\hline & Al-K & Ti-K \\
\hline Ti(1)_pt1 & 256 & 33722 \\
\hline \multicolumn{3}{|c|}{ Weight $\%$} \\
\hline & Al-K & Ti-K \\
\hline Ti(1)_pt1 & 0.41 & 99.59 \\
\hline \multicolumn{3}{|c|}{ Atom \% } \\
\hline & Al-K & Ti-K \\
\hline Ti(1)_pt1 & 0.73 & 99.27 \\
\hline \multicolumn{3}{|c|}{ Formula } \\
\hline & Al-K & Ti-K \\
\hline Ti(1)_pt1 & $\mathrm{Al}$ & $\mathrm{Ti}$ \\
\hline
\end{tabular}

Figure 2. EDS analysis obtained for pure Ti surface.
Spin-coating Ti with CAP, a very simple and rapid method, yielded CAP layers $(65 \pm 5) \mathrm{nm}$ thick, Ti substrates became smoother and more adequate for adsorption study purposes. Scanning electron micrographies showed that CAP coated Ti surfaces became smoother and that the scratches disappeared (Figure 4a). AFM images (Figure 4b) obtained for CAP coated Ti surfaces also evidenced homogeneous profiles and low roughness values $(\mathrm{rms}=0.7 \mathrm{~nm})$. Coating Therefore, Ti surfaces with CAP provided more homogeneous substrates, making possible the study of adsorption of biomolecules by means of ellipsometry and AFM.

Not only implant surface roughness plays an important role on the adhesion of proteins and cells, but also implant surface wettability. For instance, very hydrophobic surfaces might induce undesirable protein unfolding ${ }^{18}$. Surfaces are considered as hydrophobic when advancing contact angle is close to $90^{\circ}{ }^{15}$. Pure Ti surfaces presented mean advancing and receding contact angles of $(60 \pm 1)^{\circ}$ and $(36.5 \pm 0.5)^{\circ}$ (Table 1), respectively. The advancing contact angle is close to that

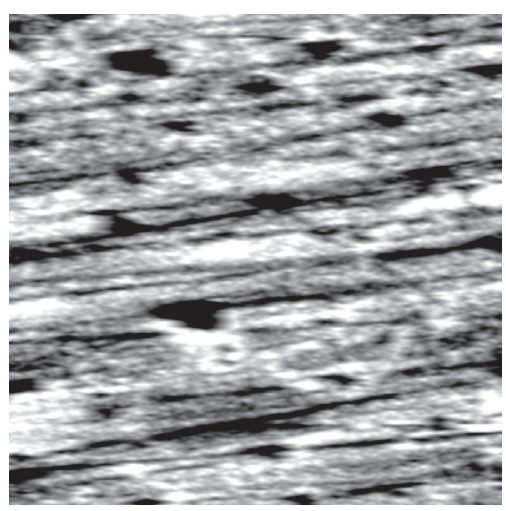

(a)

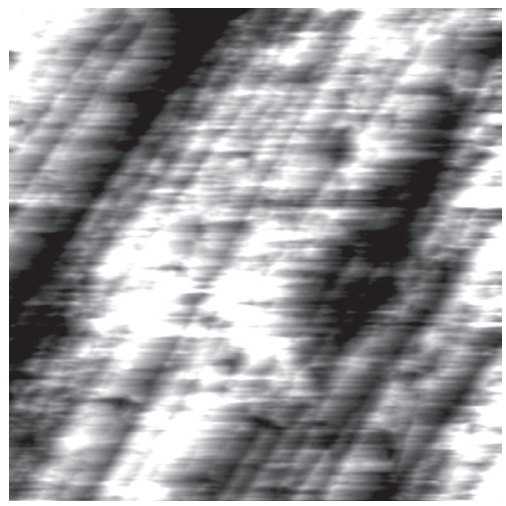

(b)

Figure 3. AFM topographic images corresponding to scan areas of $(20 \times 20) \mu \mathrm{m}^{2}$. a) pure $\mathrm{Ti}, \mathrm{Z}=160 \mathrm{~nm}$; and b) $\mathrm{LYZ}$ adsorbed onto $\mathrm{Ti}, \mathrm{Z}=70$ $\mathrm{nm}$.

Table 1. Mean values of advancing $\left(\theta_{\mathrm{A}}\right)$ and receding $\left(\theta_{\mathrm{R}}\right)$ contact angles, hysteresis in the contact angle $\left(\Delta \theta=\theta_{A}-\theta_{R}\right)$ and roughness (rms) determined for Ti, CAP coated Ti discs (Ti-CAP) and lysozyme adsorbed onto Ti-CAP (Ti-CAP-LYZ).

\begin{tabular}{lcccc}
\hline \multicolumn{1}{c}{ Surface } & $\theta_{\mathrm{A}}\left({ }^{\circ}\right)$ & $\theta_{\mathrm{R}}\left(^{\circ}\right)$ & $\Delta \theta\left(^{\circ}\right)$ & $\mathrm{rms}(\mathrm{nm})$ \\
\hline Ti $(20 \times 20 \mu \mathrm{m})$ & $60 \pm 1$ & $36.5 \pm 0.5$ & $23.5 \pm 0.5$ & $32 \pm 2$ \\
Ti-CAP $(2 \times 2 \mu \mathrm{m})$ & $74 \pm 1$ & $67.5 \pm 0.5$ & $6.5 \pm 0.5$ & 0.7 \\
Ti-CAP- LYZ & $53 \pm 1$ & $34 \pm 1$ & $19 \pm 1$ & 0.9 \\
$(0.6 \times 0.6 \mu \mathrm{m})$ & & & & \\
\hline
\end{tabular}


reported in the literature as $(55 \pm 4)^{\circ} 2,3$. The large hysteresis value of $(23.5 \pm 0.5)^{\circ}$ results from the large surface roughness, as already observed by AFM and SEM images. Upon coating Ti discs with CAP films mean advancing contact angle increased to $(74 \pm 1)^{\circ}$, indicating some hydrophobicity caused by the orientation of propyl groups to the air (Table 1). Similar surface property has been observed for thin cellulose ester films onto Si wafers ${ }^{8}$. The low hysteresis value of $(6.5 \pm 0.5)^{\circ}$ corroborates with the smooth surface observed by AFM and SEM (Figure 4).

\subsection{Protein adsorption}

The adsorption isotherms obtained for LYZ onto CAP coated Ti/ $\mathrm{TiO}_{2}$ in water, $\mathrm{NaCl} 0.1$ and $0.2 \mathrm{~mol} . \mathrm{L}^{-1}$ are shown in Figure 5. The adsorbed amount values increased with LYZ concentration up to a plateau value $\Gamma_{\text {plateau }}$. Mean $\Gamma_{\text {plateau }}$ value increased from $(2.3 \pm 0.3)$ to (4.1 \pm 0.7$) \mathrm{mg} \cdot \mathrm{m}^{-2}$, when salt has been added to the system. CAP films are uncharged surfaces, so that interactions of coulombic nature can be discharged. However, under $\mathrm{pH} 6, \mathrm{LYZ}$ molecules have positive net charge. Upon adding some salt, LYZ charges are screened, so that intermolecular repulsive interactions decreased, favoring non-electrostatic

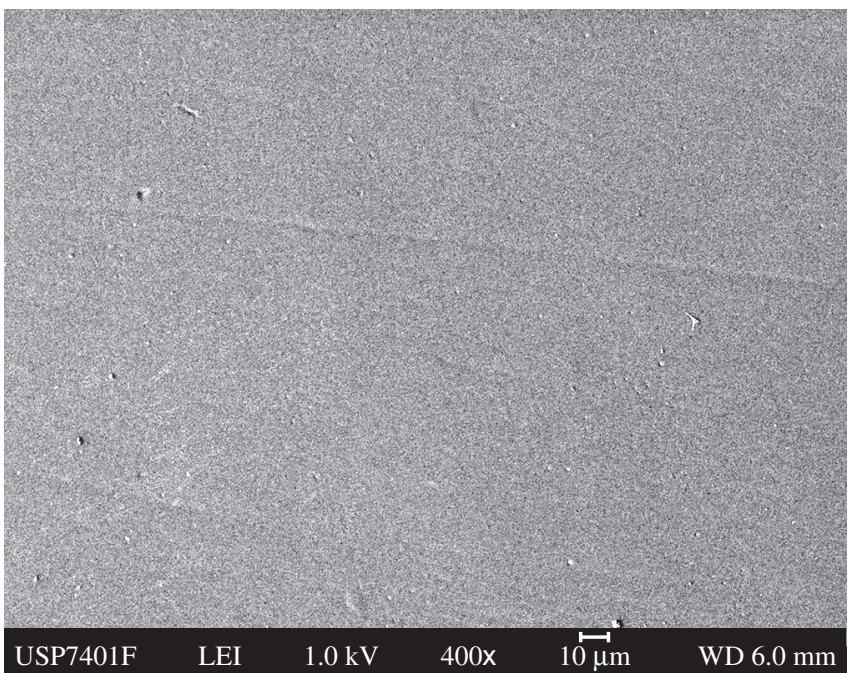

(a)

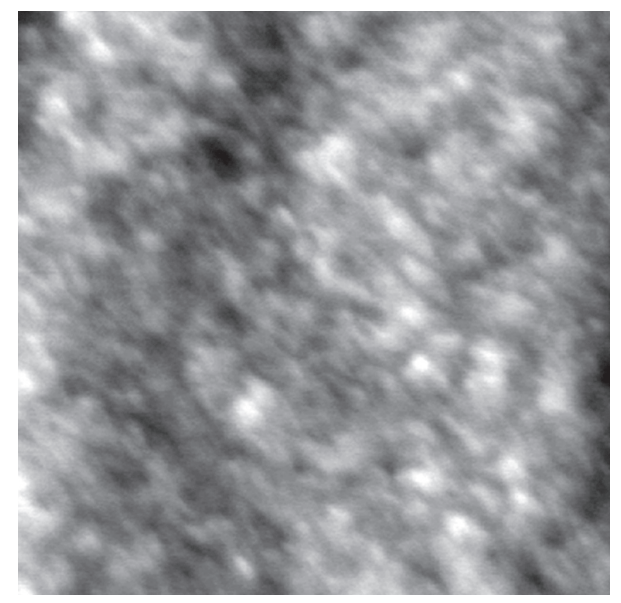

(b)

Figure 4. Topographic images of CAP-coated Ti discs obtained by means of a) SEM; and b) AFM, $(2 \times 2) \mu m^{2}, Z=10 \mathrm{~nm}$. interactions, as van der Waals interactions, between CAP surfaces and LYZ uncharged residues. It is interesting to notice that LYZ presents a terminal sequential portion predominately hydrophobic, which is composed of Met 1, Leu 4, Leu 5, Ile 6, Leu 7, Val 8, Leu 9, Phe 11, Leu 12, Pro 13, Leu 14, Ala 15, Ala16, Leu 17, Val 20, Phe $21^{10}$. Such hydrophobic sequence might act as a block, binding to CAP propyl groups. The decrease of mean advancing angle value from $(74 \pm 1)^{\circ}$ to $(53 \pm 1)^{\circ}$ observed for CAP covered Ti after LYZ adsorption (Table 1) supports the idea that LYZ hydrophobic residues are oriented to CAP films, while LYZ hydrophilic residues are exposed to the air. Preferential molecular orientation of adsorbed proteins and enzymes has been often observed ${ }^{8,13,19-21}$. For comparison, upon adsorbing lipase or bovine serum albumin onto CAP films $\sim 2.0 \mathrm{~nm}$ thick the advancing angle value decreased about 20 degrees $^{8}$, indicating the exposition of hydrophobic residues to the surface and hydrophilic residues to the air.

Figure 6 shows topographic image of LYZ adsorbed onto CAP coated Ti under $\mathrm{NaCl} 0.2$ mol. $\mathrm{L}^{-1}$. The adsorbed amount corresponded to the plateau region. One notices the presence of small spherical entities with height ranging from $1.0 \mathrm{~nm}$ to $1.8 \mathrm{~nm}$ on the surface. They were attributed to adsorbed LYZ molecules, since the hydrodynamic radius of lysozyme was found to be $1.90 \mathrm{~nm}^{22}$. Similar features were observed less frequently for LYZ adsorbed onto CAP coated Ti under $\mathrm{NaCl} 0.1 \mathrm{~mol} . \mathrm{L}^{-1}$ or in pure water, corroborating with the tendency followed by $\Gamma_{\text {plateau }}$ values in Figure 5 .

Desorption experiments have been performed by dipping CAPcoated Ti samples after LYZ adsorption in pure solvent for 24 hours. After that period of time, samples have been removed, dried under a stream of $\mathrm{N}_{2}$ and characterized by ellipsometry. Desorption of less than $10 \%$ was observed, indicating that LYZ molecules adsorb irreversibly onto CAP-coated Ti.

\subsection{Cytoxiticity test and cell adhesion}

In the agar diffusion cytotoxicity assay none of tested surfaces presented clear halo around the samples, similar to the negative control, indicating no cytotoxicity effect. The microscopic observation showed no cellular alteration in the Petri dish cell culture under agar film. Positive and negative controls are used to test the assay performance, so we can conclude that Ti and CAP-coated Ti samples

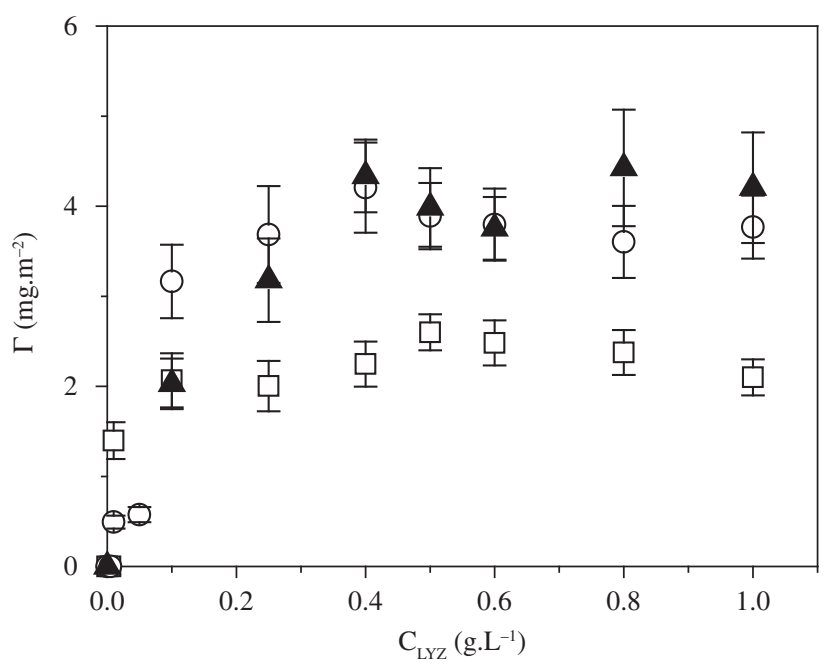

Figure 5. Adsorption isotherms obtained for LYZ onto CAP coated Ti in water (open square), $\mathrm{NaCl} 0.1$ mol.L $\mathrm{L}^{-1}$ (open circle) and $0.2 \mathrm{~mol} . \mathrm{L}^{-1}$ (solid triangle) at $25^{\circ} \mathrm{C}$. 
did not present any toxic effect and could be used in the cellular adhesion experiments.

Cellular adhesion was expressed in Figure 7 as the percentage of adhered cells with relation to seeded cells onto Ti, Ti-CAP and Ti-CAP-LYZ. Cellular adhesion onto Ti and Ti-CAP surfaces was similar. However, standard deviation was higher in the case of CAP

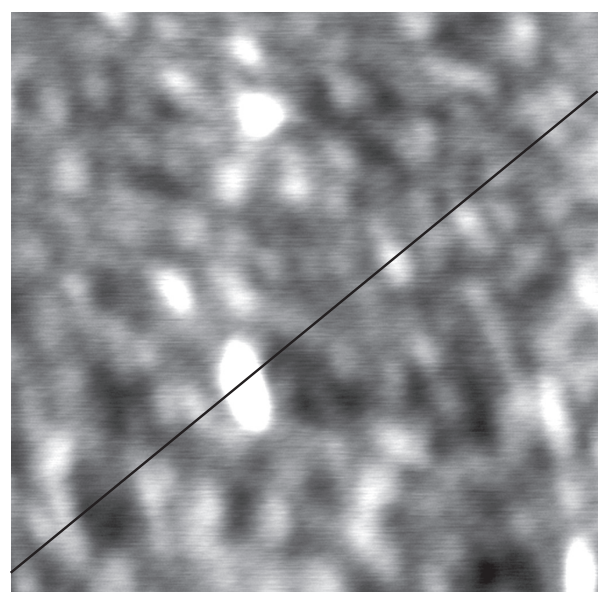

(a)

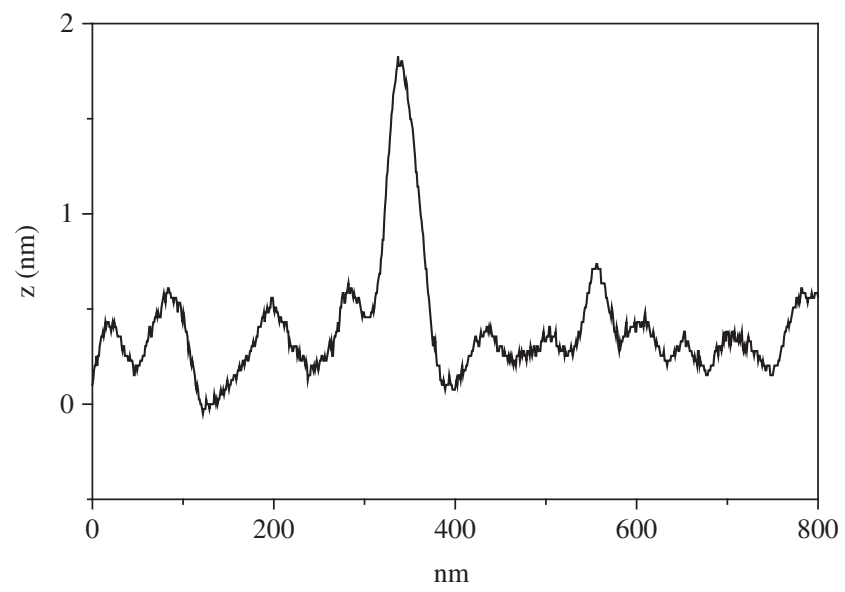

(b)

Figure 6. a) AFM topographic image $(0.6 \times 0.6) \mu \mathrm{m}^{2}$ of $\mathrm{LYZ}$ adsorbed onto $\mathrm{CAP}$ coated Ti disc; and b) the corresponding cross-section.

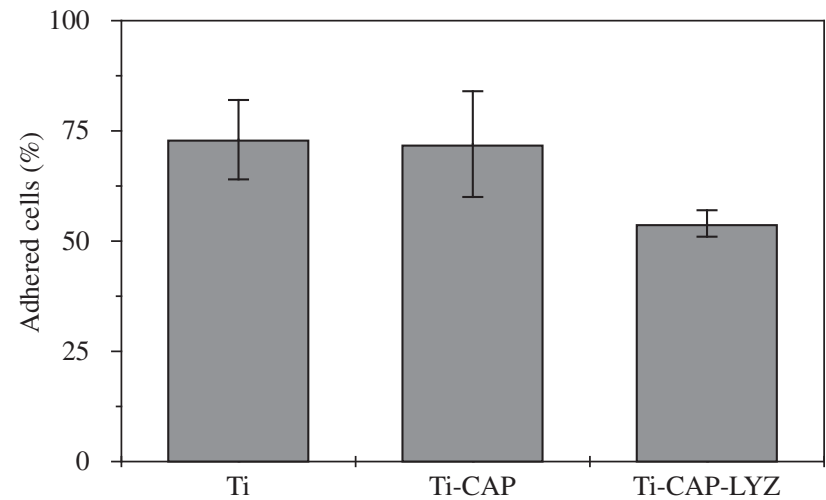

Figure 7. Percentage of adhered cells with relation to seeded cells onto pure Ti, CAP coated Ti and Ti-CAP-LYZ surfaces. coated surfaces. Ti and Ti-CAP presented very different surface profiles; the former was very rough, while the latter was flat and smooth. Correlating surface roughness and cell adhesion is not a trivial task. Mechanical interlocking can help the initial stages of cell adhesion on the surface ${ }^{23}$. On the other hand, extremely rough surfaces might disfavor cell adhesion ${ }^{4,24}$. Huang and co-workers ${ }^{4}$ tested cell adhesion on Ti surfaces (area $3.8 \mathrm{~cm}^{2}$ ) with mean roughness ranging from 0.050 to $1.20 \mu \mathrm{m}$. Optimal cell adhesion was observed for Ti surfaces with mean roughness of $0.150 \mu \mathrm{m}$. From the practical point of view this result was very important because it gives an order of magnitude for surface roughness, which provides adequate cell adhesion. Nevertheless, one should be aware that mean roughness depends strongly on the area size, which was analyzed, and on the technique. Concerning the technique, contact profilometers use tips with very large diameter (micrometer range), while non-contact AFM tips are typically $50 \mathrm{~nm}$ large. As a consequence, AFM tips penetrate depths that profilometers tips cannot reach. Another aspect is that AFM is not adequate for analyzing areas larger than $100 \times 100 \mu \mathrm{m}$ and for very rough surfaces (micrometer range) ${ }^{25}$. The influence of Ti topography on bacterial adhesion has been recently reported ${ }^{26}$. Streptoccocci adhered preferentially onto the valleys of micro-rough Ti surfaces. The authors observed that bacterial adhesion was favored when the parameters that characterize topography and roughness are in the order of bacteria dimensions ${ }^{26}$. However, the present study shows that although $\mathrm{Ti}$ and Ti-CAP surfaces present different surface topographies, cells adhered similarly onto them. One plausible explanation for this might be the molecular recognition of CAP glucopyranosyl residues by carbohydrate molecules present cell surfaces. This would also explain why cell adhesion onto Ti-CAP-LYZ was less favored, since part of CAP surface was occupied by adsorbed LYZ molecules, the number of CAP glucopyranosyl residues available is smaller than on Ti-CAP surfaces.

Fibronectin, collagen and poly-D-lysine have been often used to coat surfaces for cell cultivation. A recent $\operatorname{study}^{27}$ revealed that collagen and polylysine produce surfaces that range form hydrophobic to hydrophilic, depending on the underlying substrate, while fibronectin produces hydrophobic surface, regardless the underlying substrate. For comparison, surface energies of fibronectin and CAP amounted to $\sim 48 \mathrm{~mJ} . \mathrm{m}^{-1} 27$ and $\sim 55 \mathrm{mN} . \mathrm{m}^{-2}{ }^{28}$, respectively. These values do not differ much from surface energy determined for pure Ti, which ranged from $\sim 44$ to $\sim 55 \mathrm{~mJ} . \mathrm{m}^{-1}$, depending on the passivation and sterilization method ${ }^{29}$. Therefore, energetic aspects of CAP-coated Ti surfaces also indicate these surfaces as adequate biomaterials. Coating Ti with CAP brings not only practical but also economic advantages; coating $1.0 \mathrm{~m}^{2}$ of Ti costs $\sim$ US\$ 1.00 .

\section{Conclusions}

Coating surfaces Ti surfaces with CAP ultrathin films was presented as a low cost strategy to reduce original surface roughness, providing adequate substrates for the adsorption of biomolecules. Smooth CAP coated Ti surfaces present chemical composition rich in glucopyranosyl residues and short alkyl side groups, serving as attractive substrates for proteins and cell adhesion. Moreover, such smooth surfaces reduce contamination risks by monolayers of hydrocarbons and inorganic impurities ${ }^{30}$. CAP is a non-cytotoxic material, as evidenced by in vitro tests, and could be used for in vivo applications.

\section{Acknowledgments}

The authors acknowledge FAPESP and CNPq for financial support; Sistema de Implante Nacional (SIN, São Paulo, Brazil) and Eastman do Brasil for supplying Ti discs and CAP, respectively. 


\section{References}

1. Le Guehennec L, Soueidan A, Layrolle P, Amouriq Y. Surface treatments of titanium dental implants for rapid osseointegration. Dental Materials. 2007; 23(7):844-854.

2. Mabboux F, Ponsonnet L, Morrier J.-J, Jaffrezic N, Barsotti O. Surface free energy and bacterial retention to saliva-coated dental implant materials - an in vitro study. Colloid Surf B: Biointerf. 2007; 39(4):199-205.

3. Bagno A, di Bello C. Surface treatments and roughness properties of Tibased biomaterials. J. Mater. Sci-Mater. Med. 2004; 15(9):935-949.

4. Huang HH, Ho CT, Lee TH, Lee TL, Liao KK, Chen FL. Effect of surface roughness of ground titanium on initial cell adhesion. Biomol. Eng. 2004; 21(3-5):93-97.

5. Pitt WG, Morris RN, Mason ML, Hall MW, Luo Y, Prestwich GD. Attachment of hyaluronan to metallic surfaces. J. Biomed. Mater. Res. A. 2004; 68(1):95-106.

6. Allen LT, Tosettoa M, Miller IS, O’Connor DP, Penney SC, Lynch I, Keenan AK, Pennington SR, Dawson KA, Gallagher WM. Surface-induced changes in protein adsorption and implications for cellular phenotypic responses to surface interaction. Biomaterials. 2006; 27(16):3096-3108.

7. Edgar K J, Buchanam CM, Debenham JS, Rundquist PA, Seiler BD, Shelton MC, Tindall D. Advances in cellulose ester performance and application. Prog. Polym. Sci. 2001; 26(9):1605-1688.

8. Kosaka PM, Kawano Y, Salvadori MC, Petri DFS. Characterization of ultrathin films of cellulose esters. Cellulose. 2005; 12(4):351-359.

9. Jollès P, Jollès J. What's new in lysozyme research - always a model system, today as yesterday. Mol. Cell. Biochem. 1984; 63(2):165-189.

10. www.expasy.org ID: P00698 [cited 2007 Jun].

11. Azzam RMA, Bashara NM. Ellipsometry and Polarized Light, North Holland Publication, Amsterdam, 1987.

12. Ord JL, Smet DJ, Beckstead DJ. Eletrochemical and optical-properties of anodic oxide-films on titanium. J. Electrochem. Soc. 1989; 136(8):2178-2184

13. Almeida AT, Salvadori MC, Petri DFS. Enolase adsorption onto hydrophobic and hydrophilic solid substrates. Langmuir. 2002; 18(18):6914-6920.

14. Ortega-Vinuesa JL, Tengvall P, Lundstrom P I. Molecular packing of HSA, IgG, and fibrinogen adsorbed on silicon by AFM imaging. Thin Solid Films. 1998; 324(1,2):257-273.

15. Adamson A. Physical Chemistry of Surfaces. New York: John Wiley \& Sons; 1982.
16. Rogero SO, Malmonge SM, Lugão AB, Ikeda TI, Miyamaru L, Cruz AS. In vitro cytotoxicity test: Comparative study between two methodologies. Materials Research. 2003; 6(3):317-320.

17. ISO10993-5 Biological evaluation of medical devices Tests for cytoxicity: in vitro methods; 1992.

18. Koutsopoulos S, Patzsch K, Bosker WTE, Norde W. Adsorption of trypsin on hydrophilic and hydrophobic surfaces. Langmuir. 2007; 23(4):20002006.

19. Pancera SM, Alvarez EB, Politi MJ, Gliemann H, Schimmel T, Petri DFS. Adsorption behavior of creatine phosphokinase onto solid substrates. Langmuir. 2002; 18(9):3517-3523.

20. Pancera SM, Gliemann H, Schimmel T, Petri DFS. Adsorption behavior and activity of hexokinase. J. Coll. Interf. Sci. 2006; 302(2):417-423.

21. Naves AF, Carmona-Ribeiro AM, Petri DFS. Immobilized horseradish peroxidase as a reusable catalyst for emulsion polymerization. Langmuir. 2007; 23(4):1981-1987.

22. Kim JY, Ahn SH, Kang ST, Yoon BJ. Electrophoretic mobility equation for protein with molecular shape and charge multipole effects. J. Coll. Interf. Sci. 2006; 299(1):486-492.

23. den Braber ET, de Ruijter JE, Smots HTJ, Ginsel LA, von Recum AF, Jansen, JA. Quantative analysis of cell proliferation and orientation on substrata with uniform parallel surfce micro-grooves. Biomaterials. 1996; 14(11):1093-1099.

24. Anselme K, Linez P, Bigerelle M, Le Maguer D, Le Maguer A, Hardouin $\mathrm{P}$, Hildebrand HF, Iost A, Leroy JM. The relative influence of the topography and chemistry of TiAl6V4 surfaces on osteoblastic cell behavior. Biomaterials. 2000; 21(15):1567-1577.

25. Morris VJ, Kirby AR, Gunning AP. Atomic Force Microscopy for Biologists. London: Imperial College Press; 2004.

26. Diaz C, Cortizo MC, Schilardi PL, Saravia SGG, Mele MAFL. Influence of the nano-micro structure of the surface on bacterial adhesion. Materials Research. 2007; 10(1):11-14.

27. Harnett EM, Alderman J, Wood T. The surface energy of various biomaterials coated with adhesion molecules used in cell culture. Colloid Surf B. 2007; 55(1):90-97.

28. Kosaka PM, Kawano Y, Petri DFS. Dewetting and surface properties of ultrathin films of cellulose esters. J. Colloid Interface Sci. 2007; 316(2):671-677.

29. Kilpadi DV, Weimer JJ, Lemons JE. Effect of passivation and dry heat-sterilization on surface energy and topography of unalloyed titanium implants. Colloid Surf A: Physicochem Eng Aspects. 1998; 135(1-3):89-101.

30. Zhao G, Schwartz Z, Wieland M, Rupp F, Geis-Gerstorfer J, Cochran DL, Boyan BD. High surface energy enhances cell response to titanium substrate microstructure. J. Biomed. Mater. Res. 2005; 74(A):49-58. 